\title{
O TERREIRO DE UMBANDA COMO ESPAÇO DE CUIDADO: ALGUMAS REFLEXÕES
}

\section{THE UMBANDA TERREIRO AS A CARE SPACE: SOME REFLECTIONS}

\section{EL TERREIRO DE UMBANDA COMO ESPACIO DE CUIDADOS: ALGUNAS REFLEXIONES}

\author{
Antonio Marcos Tosoli Gomes ${ }^{1}$
}

Como citar este artigo: Gomes AMT. O terreiro de umbanda como espaço de cuidado: algumas reflexões. Rev baiana enferm. 2021;35:e45202.

Este texto parte de uma reflexão levada a cabo ao longo dos últimos três anos, desenvolvendo pesquisas participantes e distintas observações em diferentes terreiros de umbanda da cidade do Rio de Janeiro e na região metropolitana da capital do estado homônimo. A reflexão centra-se na premissa de que estes terreiros se constituem como um espaço de cuidado à saúde e como um tempo de possibilidades de autoconhecimento e de novas atitudes diante da vida. Tentaremos levar à frente esta argumentação baseada em quatro aspectos principais, quais sejam: o acolhimento na comunidade religiosa; o desenvolvimento do diálogo com os umbandistas em transe, que, para os fiéis, é a corporificação de entidades espirituais e transcendentes, disponíveis para a conversa frente a frente; a inclusão das diferentes facetas da vida humana neste atendimento; e o retorno ao cotidiano e aos seus desafios.

Antes de abordar especificamente os tópicos que foram apontados, destaca-se que, dentre outras definições expostas, umbanda significa a arte ou a maneira de curar e de encantar ${ }^{(1)}$. Um dos seus principais ritos, públicos, a gira, possui origem etimológica na ideia de caminho e de travessia ${ }^{(1)}$, o que conforma uma conceptualização de movimento e de dinâmica e tende a configurar uma abordagem complexa e não estática da vida de um modo geral e do processo saúde-doença, em particular.

Protelando por um parágrafo a mais a entrada nos tópicos elencados, há de se considerar a ideia de encantamento e precisá-lo, na medida do possível, de forma um pouco melhor ${ }^{(2)}$. Por um lado, relaciona-se com o transcendente, aquilo que existe para além da realidade palpável, mediante crenças da comunidade religiosa em seres concretos que entraram neste universo: malandros que ensinam o bem viver coletivo $^{(3)}$, pombagiras que elevam a autoestima feminina em função do próprio ser feminino ${ }^{(4)}$ e pretos velhos que fazem, da paciência, a resistência firme e crítica diante das impossibilidades, enraizando-se na esperança como uma forma incontrolável de ser no mundo ${ }^{(5)}$. Por outro lado, com isso,

Enfermeiro. Doutor em Enfermagem. Professor Titular da Faculdade de Enfermagem da Universidade do Estado do Rio de Janeiro. Pesquisador Nível 1D do Conselho Nacional de Desenvolvimento Cientíico e Tecnológico e Procientista da Fundação de Amparo à Pesquisa do Estado do Rio de Janeiro. Rio de Janeiro, Rio de Janeiro, Brasil. mtosoli@gmail.com. https://orcid.org/0000-0003-4235-9647. 
possibilita o encantamento da vida em seus paradoxos, em suas contradições e até mesmo em suas limitações, gerando perspectivas de futuro, mas com esta totalidade da existência, de modo integrado e integrativo.

Com relação ao primeiro tópico, o processo de acolhimento na comunidade religiosa, deve-se destacar que ele possui diferentes camadas de aprofundamento, dentre as quais serão destacadas algumas. A primeira é que, conhecer um terreiro de umbanda é encontrar o Brasil e defrontar-se com diferentes facetas da brasilidade, desde as imagens sacras presentes nos terreiros, as práticas religiosas populares construídas ao longo dos últimos séculos e o transe de religiosos com características de populações do cotidiano brasileiro (indígenas e pretos-velhos, por exemplo) que atendem ao público ${ }^{(2,6)}$. Há também uma familiaridade quando se considera que as racionalidades sobre a saúde e a doença ali presentes são aquelas consideradas como leigas ${ }^{(7)}$, o que permite um diálogo mais fluido e uma compreensão mútua mais frequente e consistente.

Além disto, consulentes (os que procuram atendimento) e os religiosos que entram em transe e, assim, fazem os atendimentos, são atores sociais à espera da intervenção de um terceiro que lhes envolve e dá sentido à presença de ambos naquele espaço: a entidade espiritual. Nesse sentido, embora haja diferenças entre os consulentes e os umbandistas que entram em transe na inserção no terreiro, no acesso aos bens sagrados e no conhecimento espiritual, a decisão final está para além de ambos, o que gera solidariedade no acolhimento e no atendimento entre eles.

A segunda dimensão, a do diálogo, configura-se como a possibilidade de acesso ao sagrado em um contato íntimo, pessoal, não repetível e exclusivo ${ }^{(8)}$, o que permite a expressão das questões importantes à existência, o acolhimento mediante uma escuta atenta e as possibilidades de sínteses necessárias à continuidade do viver, buscando melhor qualidade de vida e maior construção de sentido à existência. Dessa maneira, como considera determinados autores ${ }^{(7)}$, a umbanda apresenta-se como um espaço/tempo capaz de abordar e de atender as pessoas de modo holístico, integral e integrador.

Pode-se observar no movimento dos consulentes do terreiro que o acesso ao diálogo com os religiosos em transe se configura como um momento singular, de resgate da importância da história pessoal e de seu desenrolar sobre o mundo, bem como do estímulo à autoestima, ao bom humor e à confiança na vida. Uma das primeiras observações realizadas nas pesquisas desenvolvidas neste período foi o atendimento de um Exu a uma mulher que se encontrava muito próxima do pesquisador: ele a colocou sentada, preparou uma bacia com água e ervas na sua presença e depois começou a passar aquela água em sua perna, conversando com ela por aproximadamente duas horas ininterruptas.

De modo geral, após o atendimento, os consulentes se referem à importância de serem ouvidos, à necessidade de continuar o tratamento indicado nas unidades de saúde pelo "casaca branca" (expressão comum para médicos, em específico, e às vezes para profissionais de saúde de um modo geral na linguagem recorrente das entidades nos terreiros de umbanda), à valorização da vida, ao cultivo da vida espiritual como um caminho terapêutico e ao sentimento de que não se está sozinho nos desdobramentos possíveis da situação dialogada. Esse conjunto de ações, atitudes e construções simbólicas permite a elaboração de sentido diante da vida, dos acontecimentos que as atravessa e do futuro que se mostra no horizonte.

Outro aspecto a ser destacado nessa questão do diálogo entre o consulente e o religioso em transe é que a entidade que ambos acreditam estar ali, pode ser considerada alguém próximo do humano, cabendo dentro do título de gente como a gente ${ }^{(9)}$. Suas histórias, sua personalidade, suas qualidades e também seus percalços e até mesmo defeitos são expostos nessas conversas, oferecendo dicas para o bem viver com base em suas próprias experiências, como bem aponta a obra realizada mediante entrevistas com uma mãe de santo em transe, chamada Teologia da Malandragem ${ }^{(3)}$.

Como já apontado em outros momentos ao longo do texto, mas cabe aqui realizar uma síntese, esse diálogo aborda diferentes facetas da vida humana, mas possui, de maneira recorrente, dois aspectos 
centrais, a saúde física e a saúde mental, ambos se constituindo como um desafio inerente ao enfrentamento de doenças que podem ser consideradas pela comunidade religiosa e pelo grupo social como físicas e espirituais. De um modo geral, há uma visão de entrelaçamento dessas situações constituindo o ser humano como físico e espiritual, imanente e transcendente, objetivo e subjetivo simultaneamente, tornando sua abordagem complexa e multifacetada.

$\mathrm{Na}$ esteira desta abordagem integral do humano, são englobados aspectos da vida cotidiana, os afetos, as oportunidades profissionais, as relações familiares, a vida sexual, os processos de adoecimentos, as demandas da vida espiritual, a análise das decisões tomadas na vida, os avisos de perigos que estão à espreita e os conselhos para o bem viver, dentre outras questões que poderiam ser citadas. Em contextos pré-pandêmicos, este encontro frequentemente era finalizado com abraços entre o religioso em transe e o consulente, bem como com palavras de apoio e de estímulo a seguir em frente e a ser forte.

O retorno à vida cotidiana, ao dia a dia, tende a se dar sob o signo do cuidado divino e da construção de sentido diante da possibilidade deste cuidado. Inclui, de maneira especial, a gestação da esperança na esteira do tempo da vida humana como fruto desse sentido, amadurecido nas encruzilhadas do encontro entre o divino e o humano. O terreiro se caracteriza, então, como uma encruzilhada, isto é, um espaço em que o divino adquire corpos através dos religiosos, e os consulentes podem ter relação com ele, tocá-lo e ouvi-lo, em diferentes dimensões.

Como pontuado por autores ${ }^{(2)}$, a umbanda se caracteriza pelo fenômeno do cruzo, do encontro e do encantamento; do humano com o divino; dos atores sociais consigo mesmos e com os outros, a alteridade; do passado com o presente, os negros escravizados e os malandros das ruas com os homens e as mulheres da contemporaneidade em sua cotidianidade; do presente com o futuro, pela crença no cuidado divino nos diferentes caminhos da vida humana, em que os homens e mulheres dos dias de hoje são envoltos pelo poder dos que viveram no passado e se encantaram; e do mundo cosmopolita para o chão do Brasil, sustentado pelas pessoas comuns que vivem o cinzento cotidiano.

Por isso, ao fim desta argumentação, reforça-se a ideia inicial de que os terreiros se constituem como um espaço de cuidado à saúde e como um tempo de possibilidades de autoconhecimento e de novas atitudes diante da vida, em função do sentido que se constrói coletivamente e que se acredita, ao menos para a multidão de pessoas que passam por esse complexo espaço/tempo chamado terreiro, profundamente marcado pelo Divino. Nele, há dores, velas, abraços, escuta, conhecimento, manutenção de uma sabedoria específica, flores e seres humanos se constituindo como tais e reconstruindo suas vidas diante das impossibilidades da existência e da característica ontológica da limitação e da morte que nos é própria.

\section{Contribuições:}

O autor é responsável pela concepção do projeto, análise e interpretação dos dados, redação do artigo, revisão e aprovação final da versão a ser publicada, e por todos os aspectos do trabalho, na garantia da exatidão e integridade de qualquer parte da obra.

\section{Referências}

1. Assis Junior A. Dicionário Kimbundo-Português: linguístico, botânico, histórico e corográfico. Luanda: Argente, Santos \& Cia Ltda; 1947

2. Simas LA, Rufino L. A ciência encantada das macumbas. Rio de Janeiro: Mórula; 2018.

3. Marques AC. Teologia da malandragem: a arte de viver de mestre malandrinho da Umbanda. Rio de Janeiro: Via Veritas; 2019. 
4. Lages SRC. Sustentabilidade na Umbanda: cultura, subjetividade e sexualidade feminina. Sacrilegens [Internet]. 2006 [cited 2021 Jun 15];3(1):1-14. Available from: https://periodicos.ufff.br/index.php/sacrilegens/article/ view/26378/18182

5. Rezende LL. Enxergando os mortos com os ouvidos: a reelaboração da memória da escravidão por meio da figura umbandista dos pretos-velhos. Afro-Ásia. 2018;(57):55-80. DOI: http://dx.doi.org/10.9771/aa.v0i57.23442

6. Simas LA. Pedrinhas miudinhas: Ensaios sobre ruas, aldeias e terreiros. 2a ed. Rio de Janeiro: Mórula; 2019.

7. Silva LMF, Scorsolini-Comin F. Na sala de espera do terreiro: uma investigação com adeptos da umbanda com queixas de adoecimento. Saude soc. 2020;29(1):e190378. DOI: http://dx.doi.org/10.1590/s0104-12902020190378

8. Volponi R, Chiachiri R. O ato de compreender na consulta mediúnica: um diálogo ensaístico entre guia, médium e consulente no terreiro de umbanda. Folios [Internet]. 2018 [cited 2021 Jun 11];40:179-94. Available from: https://revistas.udea.edu.co/index.php/folios/article/view/338486

9. Rotta R. Espíritos da Mata: sentido e alcance psicológico do uso ritual de caboclos na umbanda [tese]. Ribeirão Preto (SP): Universidade de São Paulo; 2010.

Recebido: 25 de junho de 2021

Aprovado: 13 de julho de 2021

Publicado: 25 de agosto de 2021

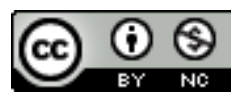

A Revista Baiana de Enfermagem utiliza a Licença Creative Commons - Atribuição-NãoComercial 4.0 Internacional.

https://creativecommons.org/licenses/by-nc/4.0/

Este artigo é de acesso aberto distribuído sob os termos da Licença Creative Commons (CC BY-NC).

Esta licença permite que outros remixem, adaptem e criem a partir do seu trabalho para fins não comerciais.

Embora os novos trabalhos tenham de lhe atribuir o devido crédito e não possam ser usados para fins comerciais, os usuários não têm de licenciar esses trabalhos derivados sob os mesmos termos. 